\title{
New Publisher for JASMS
}

A s we start a new year, we also start a new era in the life of the Journal of the American Society for Mass Spectrometry. As most of you were probably already aware, there is a new publisher of JASMS. As you have noticed from the front cover and will see as you browse through this month's issue, there is also a new look to the Journal. Such change does not happen without considerable thought and effort, so we felt it would be appropriate to share some background on the process that led us to where we are today and to give thanks at this appropriate time of year (at least in the US) to the people who have worked with us for many years.

In the summer of 2009 as the contract for publication of $J A S M S$ was nearing its final year, the ASMS Board decided that for the first time since the inception of JASMS we should have an open solicitation for proposals to be the JASMS publisher. This decision was driven not by dissatisfaction with the then publisher Elsevier, with whom we had had a very good and successful 20-year partnership. Rather, we recognized that the publishing world has undergone, and will continue to undergo, major changes. A couple of other publishers had indicated a strong desire to work with ASMS to publish JASMS, and so the ASMS Board felt that it would be prudent to explore a variety of visions for the Journal going forward rather than just negotiating a new 5- year contract with Elsevier.

To start this journey, in what I (GLG) consider has possibly been the best investment of ASMS money during my term on the Board, we hired as consultants the KaufmanWillis Group to help guide us through the process of evaluating and negotiating with potential publishers. A request for proposals was developed and a number of publishers, including the American Chemical Society, Elsevier, Springer, and Wiley-Blackwell were invited to respond. Several publishers responded, some decided not to respond, and three publishers, Elsevier, Springer, and WileyBlackwell, were invited to make a presentation to an ad hoc ASMS committee.

Each of the three publishers brought a team to a November 2009 meeting in Baltimore to present their proposal to the ASMS committee comprised of John Engen, ASMS Member-at-Large for Publications; Judith Sjoberg, ASMS Executive Director; Michael Gross, JASMS Editorin-Chief; Joyce Neff, JASMS Managing Editor; Gary Glish, ASMS President; and Cara Kaufman and Alma Willis from our consulting group. The three companies were evaluated as potential publishers on a range of criteria. They each had very different visions on the future directions of JASMS and the ASMS/publisher relationship, and very different financial models. The ability of Kaufman/Willis to distill this apples-to-oranges-to-grapes comparison into a common set of metrics was invaluable. The committee decided that the proposals from Springer and Wiley-Blackwell stood out.

The ASMS committee, with the addition of Barbara Larsen, ASMS Past-President, and Cara Kaufman then made a site visit to the two finalists in early January 2010. During the site visits further negotiations took place with each of the finalists and Springer emerged as the clear choice. This was based both on their commitment to JASMS as a scholarly journal and the financial component of their proposal. Unlike many professional societies, ASMS does not view its Journal as an income source for the society, but as a member benefit promoting our field. At the same time though, we want to minimize the financial burden and risk to the Society, which the new contract with Springer does.

By mid-February 2010 we had a preliminary contract with Springer, which was approved by the ASMS Board of Directors, and in April, we had the final contract and approved it. The first stage of the process was complete and ASMS had a new partner for the publication of JASMS. While all the people mentioned above made significant contributions, it was John Engen's tireless, efficient work that stood out, and he deserves a special thanks.

The next step was the transition from Elsevier to Springer. Obviously there is a lot of behind the scenes work involved to go from an electronic document generated by an author to the published article in an issue of JASMS. Fortuitously (i.e., not a consideration in selecting the publisher), Springer uses the same web-based platform for the editorial process as Elsevier, which made it relatively easy to transfer archival author, reviewer, etc. data. This also means that the format that authors, reviewers, and editors have been using for JASMS essentially has not changed. A big thanks goes to Joyce Neff, JASMS Managing Editor, for spearheading the transition.

Overall there are many, many people who played a role in the process that resulted in this issue of the Journal you are now reading. While we can't list them all here, there are a few who deserve a special note of gratitude. We wouldn't have made it here without the wonderful guidance of our consultant Cara Kaufman. From our new partners at Springer, Mindy OkuraMarszycki, Publishing Editor, and Carolyn Honour, Editorial Director, have been involved in the process since the beginning 
and will be an integral part of the JASMS/Springer team. Henk van der Rijst, Executive Vice President, Global Publishing, and Paula Gantz, Director, Society Relations were key players in the Baltimore meeting and site visit with Springer.

As we go forward though, we do not want to forget our past and the successful 21-year run we had with Elsevier as our partner. Our original selection of Elsevier as publisher was spearheaded by Ron Hites, president of ASMS in 1990, and Bob Murphy (vice president for programs). Our contacts with Elsevier in those "early days" were Peter Shepherd, Paul Weisslogel, Publishing Directors, Jonathan Wiener, and Greg Giblin who managed the journal for a short time. Since then, we worked with a number of publishers and desk editors, and we want to acknowledge all of them. Among our journal publishers with whom we worked for many years and who played a major role in the evolution of $J A S M S$ are Nick Baker, Egbert van Wezenbeek, and Karel Nederveen. Others who worked with us for shorter periods of time are Graeme Whitley, Laura ter Haar, Swan Go, Jon Glover, and Rob van Daalen. There have been journal managers who handled the publication duties. We wish to thank Chris Auger, our most recent journal manager, Julia Macklin, and especially Marian Ato, who worked so diligently on behalf of the journal and the authors for many years. We also thank the numerous copy editors who helped us.

We look forward to a new era for JASMS and productive interactions with Springer, our new partner in bringing this journal to the ASMS membership and the scientific community.

\section{Gary Glish}

Past President, ASMS

University of North Carolina

Chapel Hill, NC

e-mail: glish@unc.edu

Michael Gross

Editor-in-Chief, JASMS

Washington University

St. Louis, MO

e-mail:mgross@wustl.edu 